\title{
Infrared Thermography and X-Ray Tomography for Non-Destructive Evaluation of Micro-defects in CFRP
}

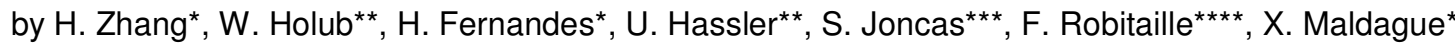 \\ * Computer Vision and Systems Laboratory, Department of Electrical and Computer Engineering, Université \\ Laval, 1065, av. de la Médecine, Québec, QC G1V 0A6, Canada, hai.zhang.1@ulaval.ca \\ ** Fraunhofer EZRT, Flugplatzstrasse 75, 90768 Fuerth, Germany \\ *** École de Technologie Supérieure, Canada \\ **** Ottawa University, Canada
}

\begin{abstract}
In this paper, the authors use infrared thermography and X-Ray Tomography to inspect micro-porosities (diameter $0.2 \mathrm{~mm}$ to $2 \mathrm{~mm}$ ). By using a micro-lens $(1 \mathrm{X})$ and laser line thermography scanning technique (LLT), the authors define a micro-infrared thermography technique and successfully inspect massive micro-porosities of 3D CFRP. In addition, the authors use high resolution (20 microns) X-Ray tomography to inspect the same 3D carbon fiber sample. As a result, a comparative research between micro-infrared thermography and high resolution X-Ray tomography is conducted along with the corresponding conclusion. At the same time, the sizes of the micro-porosities that can be detected are also summarized following detailed investigation (hundreds of inspections) respectively using micro-infrared thermography and high resolution X-Ray Tomography.
\end{abstract}

Keywords: carbon fiber, composite, infrared thermography, X-Ray tomography, laser line thermography, microlens, micro-porosity.

\section{Introduction}

The use of carbon fiber composite materials has recently increased considerably in the aerospace industry. Along with the development of manufacturing and preform, traditional defects, for example, laminate, porosities, resin redundancy, bubble, etc., are becoming less and less important. However, micro-defects are becoming increasingly important issues [1] [2].

X-ray tomography was successfully used for interior structural defect detection of CFRP recently [3] [4] [5] [6].

In the past, Infrared thermography mostly focused on macro-defects, for example, bubble, resin redundancy, porosities, etc. [7] [8] [9]. However, related research on infrared thermography was poorly conducted on micro-defects. In fact, micro-defects are becoming a new challenge for not only infrared thermography researchers, but also the whole NDT industry.

In this paper, the authors use X-Ray tomography and infrared thermography to detect micro-porosities of CFRP. In order to obtain encouraging inspection results of infrared thermography, a micro-laser line thermography is defined. The authors obtain positive and encouraging results from the comparison of the two non-destructive evaluation methods.

\section{Description of experiment sample}

The tested sample is a T-shaped CFRP (Fig. 1). 


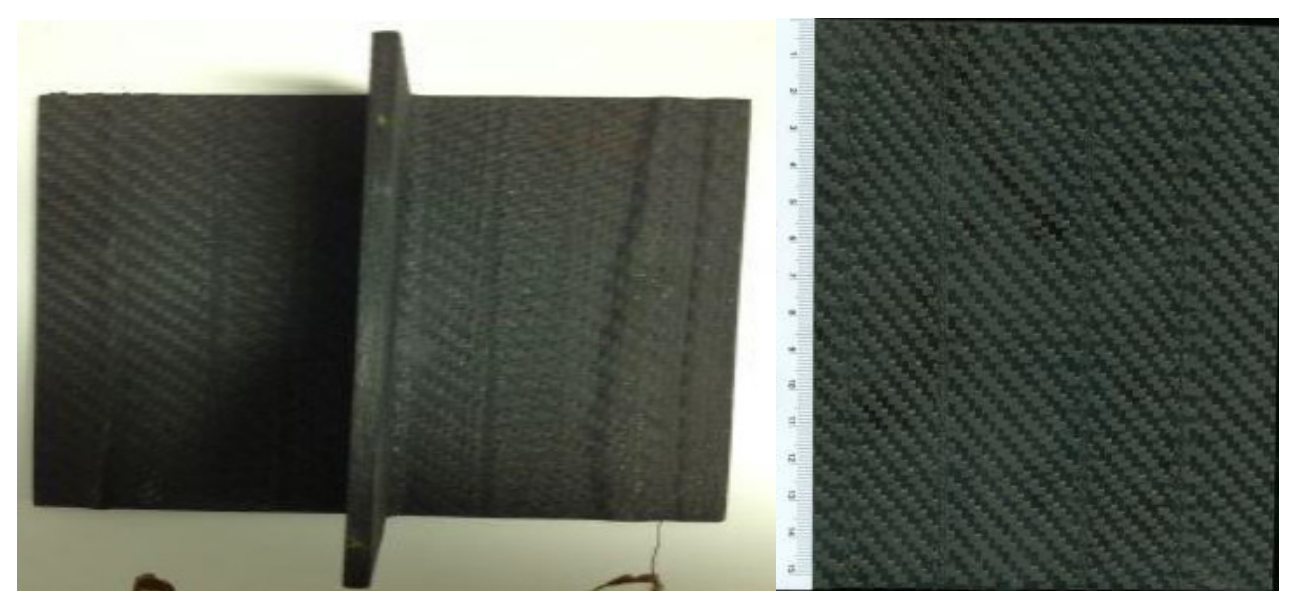

Fig. 1. Tested sample

The size of its flat section is $152 \mathrm{~mm} \times 148 \mathrm{~mm}$. 4 parallel stitching zones cross the flat section. Thousands of micro-porosities are present in the sample. Most of them are in the stitching zones.

Fig. 2 is a glass fiber sample whose interior structure is entirely the same as the tested CFRP sample. It is easier for researchers to understand the interior structure of the tested CFRP sample through the glass fiber sample, especially the stitching zones.

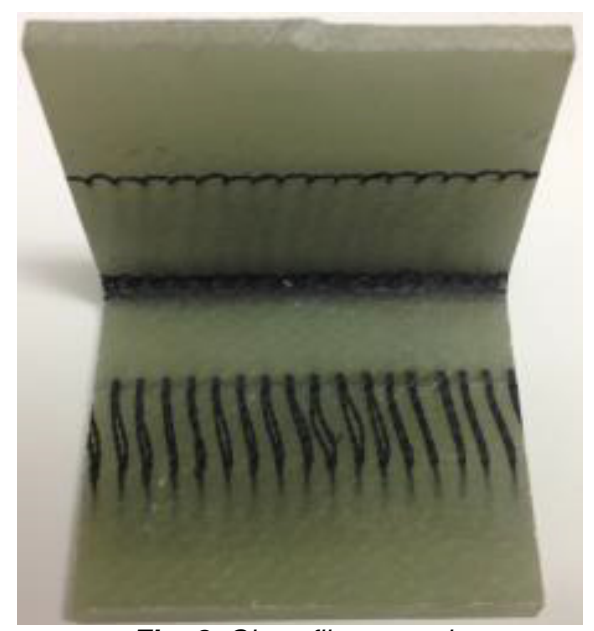

Fig. 2. Glass fiber sample

\section{X-Ray tomography inspection}

X-Ray tomography has been widely studied for many research fields, for example, medical engineering, composite materials inspection, and etc. Generally speaking, low resolution X-Ray tomography inspection is able to satisfy most industrial and commercial applications. However, high resolution X-Ray tomography inspection is becoming increasingly important and necessary at the moment.

High resolution X-Ray tomography application on composites was already conducted recently by researchers. For example, the first use of synchrotron radiation computed tomography (SRCT) was presented to achieve sub-micron resolution of damage in aerospace grade carbon fiber-epoxy composites in 2008 [10]. In 2013 [11], three optical measurement techniques were combined including digital image stereo-correlation, infrared thermography and X-Ray tomography. Their combination allows a coupled analysis of different demonstrations of the same degradation mechanisms.

The high resolution X-Ray tomography inspection was conducted in this work to detect the interior structural defects of the tested sample. The resolution used for the test is 20 microns. Fig. 3 is the X-Ray tomography inspection result. 


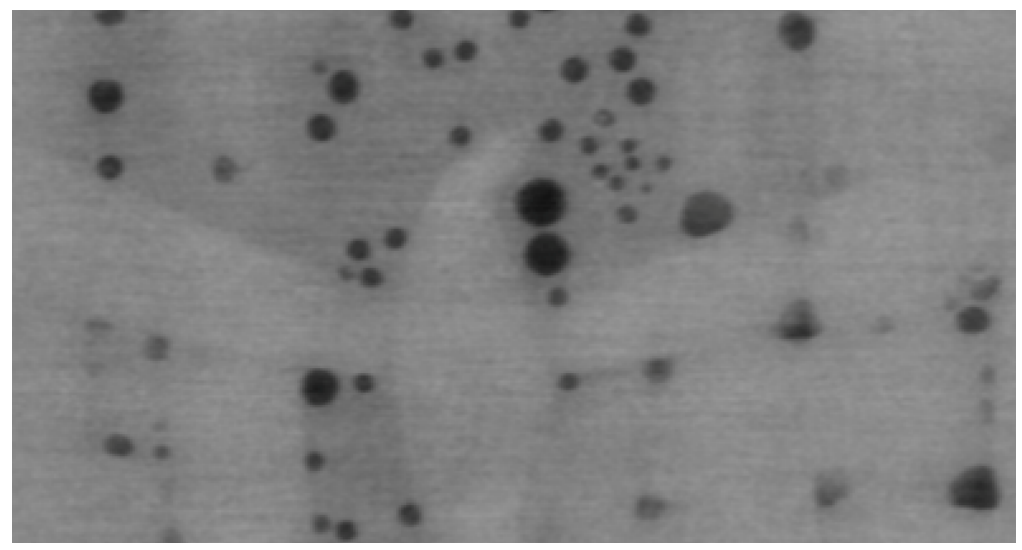

Fig. 3. X-Ray tomography inspection result

Plenty of micro-porosities were identified in the X-Ray tomography inspection result. Most of them have a diameter of approximately $0.1 \mathrm{~mm}$. Some have a slightly larger diameter of $0.2 \mathrm{~mm}$ or more. The inspection result is visually extremely clear. encouraging.

Compared to the original photo of the inspected zone in Fig 4, the X-Ray inspection result is obviously

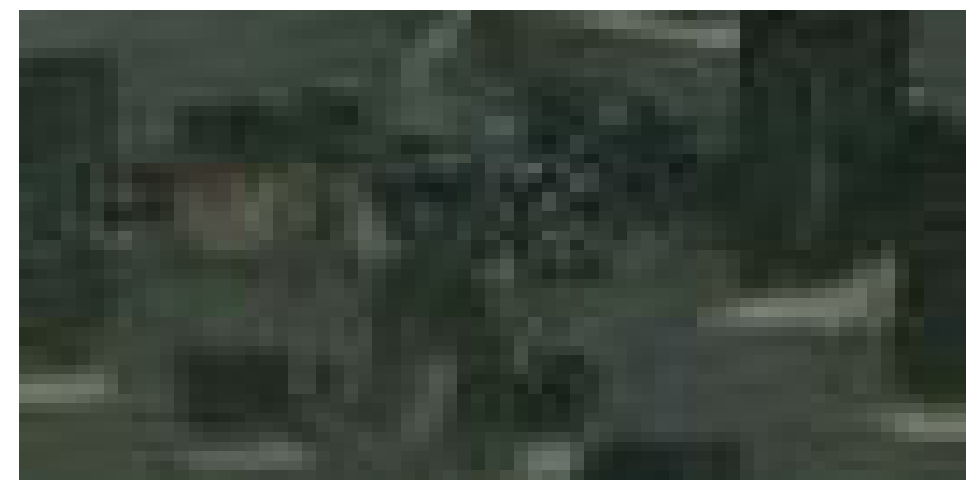

Fig. 4. Original photo of the inspected zone

Most interior micro-porosities were detected through from X-Ray tomography, a positive non-destructive evaluation method for micro-defects.

\section{Micro-laser line thermography inspection}

Conventional infrared thermography including pulsed thermography and locked-in thermography does not perform well on micro-defects [12]. Because of the existence of coupling and noise, it is extremely difficult to obtain positive inspection results from these methods.

In order to decrease these influences, the authors define a micro-laser line thermography by replacing a laser spot with a laser line in order to scan a zone quickly.

\subsection{Experimental set-up}

A micro-mirror was fixed in the middle of the micro-lens and the sample. When the mirror rotates under very high frequency, the laser spot was replaced by a laser line [12]. The sample was fixed on an arm of a robot so that the sample can move automatically (Fig. 5). The length of the laser line is $10 \mathrm{~mm}$ and the width of the laser line is $3 \mathrm{~mm}$. An inspection was carried out to scan a $10 \mathrm{~mm}$ by $152 \mathrm{~mm}$ flat zone. The laser line crosses the stitching line from $25 \mathrm{~mm}$ to $35 \mathrm{~mm}$ (distance from the left edge). The sample moved along the orientation of the stitching line automatically from $0 \mathrm{~mm}$ to $152 \mathrm{~mm}$. An experiment was carried out at every $3 \mathrm{~mm}$, so there are a total of 51 experiments ( 51 intervals of $3 \mathrm{~mm}$ to cover the entire $152 \mathrm{~mm}$ zone). 

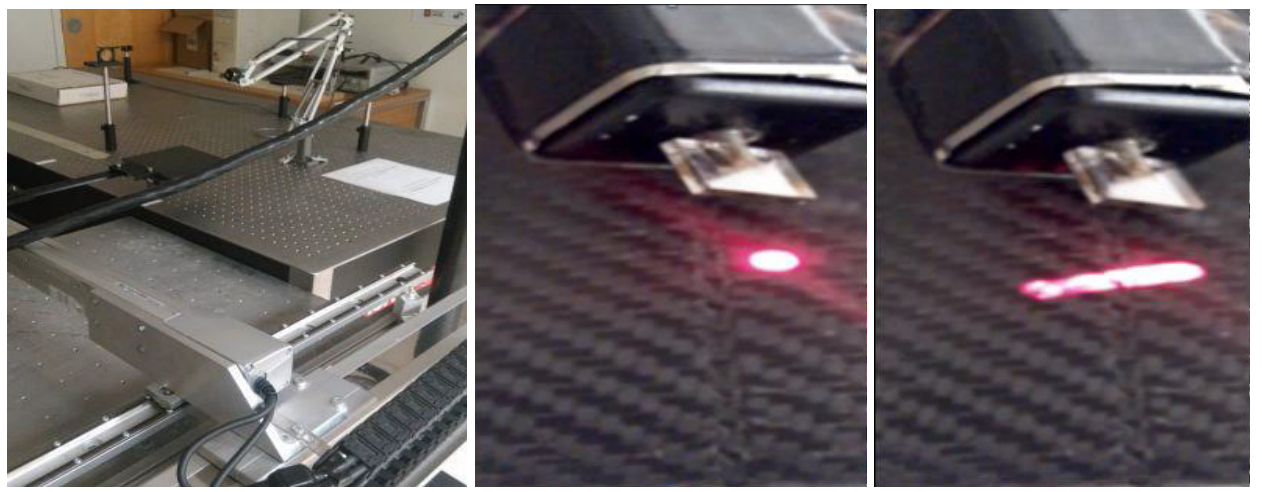

Fig. 5. Micro-laser line thermography set-up

\subsection{Inspection result}

Fig. 6 is the inspection result of the same zone as the one inspected by X-Ray tomography. From the microlaser line thermography inspection result, a couple of micro-porosities were inspected. Some of them are on the surface, and some of them are near surface. However, compared to the X-Ray tomography inspection result, only larger microporosities were inspected. Smaller micro-porosities were never detected in the micro-laser line thermography inspection result.

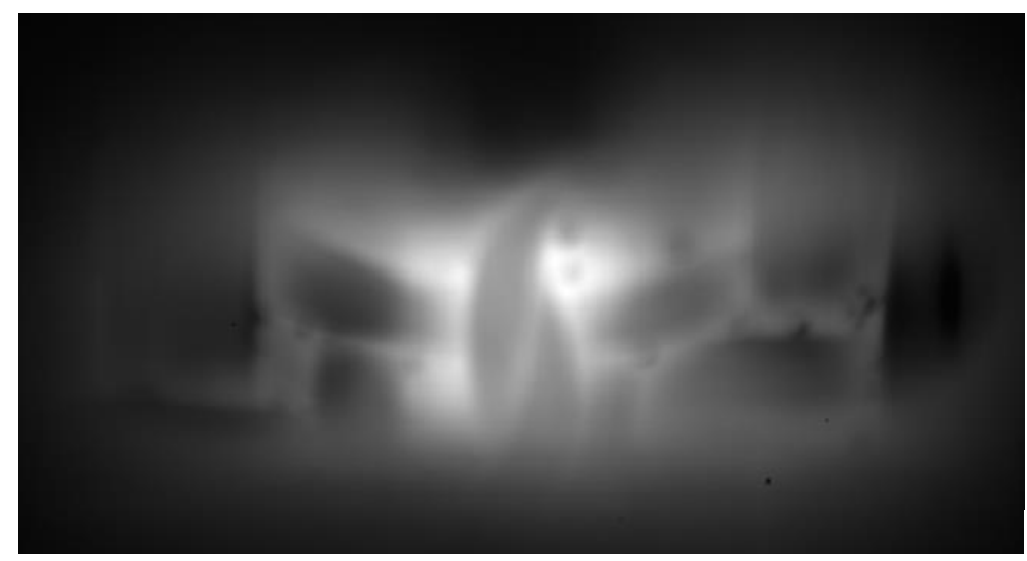

Fig. 6. Micro-laser line thermography inspection result

The micro-laser line thermography inspection result is really clearly visually. It is simple for researches to identify the micro-porosities that have been detected.

One must note that, the micro-laser line thermography inspection result was poorly processed by image processing algorithms. Further image processing results may be encouraging [13].

\section{Conclusion}

The results reported here clearly indicate that X-Ray tomography is the best solution for the inspection of microporosities. High resolution X-Ray tomography is able to detect sub-micron level defects. However, the cost of the inspection is higher since it includes the energy cost and equipment set-up.

Micro-laser line thermography is also able to detect micro-porosities. The efficiency of the inspection is much lower than X-Ray tomography. It is easy to set up the equipment. High energy is not necessary for infrared thermography. These advantages all increase the possibilities and applications of Infrared thermography. However, it is difficult to detect deeper defects. In fact, the analysis indicates that the detection depth does not exceed 80 microns. This is probably because of the diffusion of laser energy. Higher energy of laser inspection is necessary to further improve the application possibilities of this technique. Simulations conducted prior to experiments will provide valuable information and decrease the time of testing [14]. 


\section{Acknowledgement}

The authors would like to greatly acknowledge financial support provided by: Bell Helicopter and Bombardier. The authors also would like to greatly acknowledge help provided by the industrial partners: MARQUEZ, DELASTEK, CTT group, HUTCHINSON and TEXONIC.

\section{REFERENCES}

[1] Hughes M., Sebe G., Hague J., Hill C., Spear M., Mott L., "An investigation into the effects of microcompressive defects on interphase behaviour in hemp-epoxy composites using half-fringe photoelasticity", Composite Interfaces, vol. 7, iss. 1, pp. 13-29, 2000.

[2] Ohara Y., Kawashima K., "Detection of Internal micro defects by nonlinear resonant ultrosonic method using water immersion", Japanese Journal of Applied Physics, vol. 43, iss. 5B, pp. 3119-3120, 2004.

[3] Schilling P. J., Karedla B. R., Tatiparthi A. K., Verges M. A., Herrington P. D., "X-ray computed microtomography of internal damage in fiber reinforced polymer matrix composites", Composites Science and Technology, vol. 65, iss. 14, pp. 2071-2078, 2005.

[4] Schell J. S. U., Renggli M., van Lenthe G. H., Muller R., Ermanni P., "Micro-computed tomography determination of glass fibre reinforced polymer meso-structure", Composites Science and Technology, vol. 66, iss. 13, pp. 2016-2022, 2006.

[5] Shen H., Nutt S., Hull D., "Direct observation and measurement of fiber architecture in short fiber-polymer composite foam through micro-CT imaging", Composites Science and Technology, vol. 64, iss. 13-14, pp. 21132120, 2004.

[6] Fu S., Feng X., Lauke B., Mai Y., "Effects of particle size, particle/matrix interface adhesion and particle loading on mechanical properties of particulate-polymer composites", Composites Part B: Engineering, vol. 39, iss. 6, pp. 933-961, 2008.

[7] Fernandes H., Maldague X., "Use of infrared thermography to measure fiber orientation on carbon-fiber reinforced composites", in Proceedings of the $16^{\text {th }}$ International Symposium on Applied Electromagnetics and Mechanics (ISEM), in Quebec City, 2013.

[8] Fernandes H., Maldague X., "Fiber orientation assessment in carbon fiber reinforced composites using thermography", in Proceedings of the $19^{\text {th }}$ International Conference on Composite Materials, S. V. Hoa and P. Hubert, eds., 1, pp. 4970-4977, in Montreal, 2013.

[9] Maldague X., "Theory and practice of infrared technology for non-destructive testing", Wiley-Interscience, New York, $1^{\text {st }}$ ed., 2001.

[10] Wright P., Fu X., Spearing S. M., "Ultra high resolution computed tomography of damage in notched carbon fiber-epoxy composites", Journal of Composite Materials, vol. 42, no. 19, pp. 1993-2002, 2008.

[11] Goidescu C., Welemane H., Garnier C., Fazzini M., Brault R., Peronnet E., Mistou S., "Damage investigation in CFRP composites using full-field measurement techniques: combination of digital image stereo-correlation, infrared thermography and X-ray tomography", Composites Part B: Engineering, vol. 48, pp. 95-105, 2013.

[12] Zhang H., Genest M., Robitaille F., Maldague X., West L., Joncas S., Leduc C., "Infrared thermography, ultrasound C-scan and microscope for non-destructive and destructive evaluation of 3D carbon fiber materials: a comparative study", in Proceedings of SPIE 9485 Thermosense: Thermal Infrared Applications XXXVII, Sheng-Jen (Tony) Hsieh and Joseph N. Zalameda, 94850X, in Baltimore, 2015.

[13] Fernandes $H$., Maldague X., "Fiber orientation assessment on surface and beneath surface of carbon fiber reinforced composites using active infrared thermography", in Proceedings of SPIE 9105 Thermosense: Thermal Infrared Applications XXXVI, 910500X, in Baltimore, 2014.

[14] Fernandes H., Maldague X., "Fiber orientation assessment in complex shaped parts reinforced with carbon fiber using infrared thermography", Quantitative Infrared Thermography Journal, vol. 12, 2015. 